\title{
Quetiapine monotherapy in acute phase for major depressive disorder: a meta-analysis of randomized, placebo-controlled trials
}

\author{
Narong Maneeton ${ }^{1}$, Benchalak Maneeton ${ }^{1 *}$, Manit Srisurapanont ${ }^{1}$ and Stephen D Martin ${ }^{2}$
}

\begin{abstract}
Background: Schizophrenia and bipolar depression trials suggest that quetiapine may have an antidepressant effect.

Objectives: This meta-analysis aimed to determine the efficacy, acceptability and tolerability of quetiapine treatment for major depressive disorder (MDD). Only the randomized controlled trials (RCTs) comparison between quetiapine and placebo were included. The authors searched such clinical trials carried out between 1991 and February 2012.

Data sources: MEDLINE, EMBASE, CINHL, PsycINFO and Cochrane Controlled Trials Register were searched in February 2012. Study populations comprised adults with MDD or major depression.

Study eligible criteria, participants and interventions: Eligible studies were randomized, placebo-controlled trials of quetiapine monotherapy carried out in adults with MDD and presenting endpoint outcomes relevant to: i) depression severity, ii) response rate, iii) overall discontinuation rate, or iv) discontinuation rate due to adverse events. No language restriction was applied.

Study appraisal and synthesis methods: All abstracts identified by the electronic searches were examined. The full reports of relevant studies were assessed, and the data of interest were extracted. Based on the Cochrane methods of bias assessment, risks of bias were determined. The studies with two risks or less were included. The efficacy outcomes were the mean change scores of depression rating scales, the overall response rate, and the overall remission rates. The overall discontinuation rate was considered as a measure of acceptability. The discontinuation rate due to adverse events was a measure of tolerability. Relative risks (RRs) and weighted mean differences (WMDs) with 95\% confidence intervals (Cls) were computed by using a random effect model.

(Continued on next page)
\end{abstract}

\footnotetext{
* Correspondence: bkhongsa@med.cmu.ac.th

${ }^{1}$ Department of Psychiatry, Faculty of Medicine, Chiang Mai University,

Chiang Mai, Thailand

Full list of author information is available at the end of the article
} 
(Continued from previous page)

Results: A total of 1,497 participants in three RCTs were included. All trials examined the quetiapine extended-release (XR). The pooled mean change scores of the Montgomery-Asberg Depression Rating Scale (MADRS) and the Hamilton Depression Rating Scale (HAM-D) of the quetiapine-treated group were higher than those of the placebo-treated group with the WMDs $(95 \% \mathrm{Cl})$ of $-3.37(-3.95,-2.79)$ and $-2.46(-3.47,-1.45)$, respectively. All studies defined the response and remission as $\geq 50 \%$ reduction of the MADRS total score and the MADRS total score of $\leq 8$ at endpoint, respectively. The overall response and remission rates were significantly greater in the quetiapine-treated group with RRs $(95 \% \mathrm{Cls})$ of $1.44(1.26,1.64)$ and $1.37(1.12,1.68)$, respectively. The pooled discontinuation rate was not significantly different between groups with an RR (95\%Cl) of 1.16 (0.97, 1.39). The pooled discontinuation rate due to adverse event was greater in the quetiapine group with an RR ( $95 \% \mathrm{Cl})$ of $2.90(1.87,4.48)$. With respect to sleep time, the pooled mean change Pittsburgh Sleep Quality Index (PSQI) scores of the quetiapine-treated group was also significantly higher than that of the placebo-treated group [WMD (95\%CI) of $-1.21(-1.81,-0.61)]$.

Limitations: Variety of quetiapine XR doses and the small number of RCTs were key limitations of this meta-analysis.

Conclusions: Based on the limited evidence obtained from three RCTs, quetiapine XR is effective for adult patients with MDD. The high dropout rate due to adverse events suggests that some MDD patients may not be able to tolerate quetiapine XR. Due to the balance of its efficacy benefit and risk of side effects, as the overall discontinuation rate shown, the acceptability of this agent is not more than placebo. These results should be viewed as the very preliminary one. Further studies in this area are warranted.

Implication of key findings: Quetiapine may be an alternative antidepressant. However, both risk and benefit of this agent should be taken into account for an individual patient with MDD.

\section{Background}

Major depressive disorder (MDD) is a common mental illness with a lifetime prevalence rate of $6.7 \%$ (3.8\% for men and $7.5 \%$ for women) [1]. As a disabling, recurrent, and chronic condition, it is a major burden for individuals, family members, communities and health care services [2,3]. In 2000, depression was an important cause of disease burden accounting for $4.4 \%$ of the total disability adjusted life years or $12 \%$ of all total years lived with disability worldwide [4].

Common classes of agents for the treatment of MDD include selective serotonin reuptake inhibitors (SSRIs) [5,6], serotonin-norepinephrine reuptake inhibitors (SNRIs) $[7,8]$, tricyclic antidepressants (TCAs) [9-11] and monoamine oxidase inhibitors (MAOIs) [12]. Several meta-analytic findings suggest that patients with MDD may not fully respond and/or do not fully remit after receiving adequate doses and duration of these antidepressants. Only 30\%-55\% of MDD patients achieve remission state at the end of acute SSRI or SNRI treatment $[13,14]$. In addition, the overall dropout rates and the dropout rates due to adverse events are relatively high in the ranges of $25-39 \%$ and $9-17 \%$ $[15,16]$, respectively, which suggest that many MDD patients cannot accept or tolerate currently available antidepressants [17]. While these antidepressants presumably affect serotonin and norepinephrine neurotransmitters, several lines of evidence support that dopamine neurotransmitters may also play an important role in the treatment of MDD patients $[18,19]$.
Quetiapine and its mainly active metabolite, Ndesalkylquetiapine (norquetiapine), have various pharmacological effects on central serotonergic and dopaminergic receptors, which presumably involve in its efficacy for the treatment of schizophrenia [20]. Recently, norquetiapine has been found to be a potent inhibitor for norepinephrine transporter shared commonality with TCAs and SNRIs, and a moderate-to-high affinity for D2, 5HT1A, 5HT2A, and 5 HT2C receptors shared some properties with SSRIs $[20,21]$. These mechanisms of action may explain its efficacy for the treatment of depression and anxiety [21-24].

Several lines of research suggest that quetiapine may have an antidepressant effect. Some clinical trials found that quetiapine reduced depressive symptoms considerably in schizophrenic patients [25] and bipolar depression [26,27]. Although some experts view that its antidepressant effect may not be superior to other antidepressants [28], this is the only agent approved for the treatment of acute bipolar depression [29].

Recently, some randomized-controlled trials of quetiapine have been conducted in patients with MDD [30-33]. Since most of these studies have small samples, a meta-analysis, which is more powerful in estimating the true effect size, may be a strategy to confirm its efficacy and safety.

To determine the efficacy, acceptability and tolerability of quetiapine monotherapy in patients with MDD, we conducted a systematic review of randomized, placebocontrolled trials of quetiapine in these patients. 


\section{Methods}

The authors searched such clinical trials carried out between 1991 and February 2012.

\section{Eligibility criteria}

The included studies were randomized, placebocontrolled trials of quetiapine monotherapy in adults (18-65 years old) with MDD. Depressive severity was rated at baseline and during treatment with standard rating scales [34] and reported the response rate, the overall discontinuation rate or the discontinuation rate due to adverse events were included. Studies with any duration of treatment for single or recurrent major depressive episodes diagnosed by any set of criteria were included. No language restriction was applied.

\section{Information sources}

We searched MEDLINE, EMBASE, CINHL, PsycINFO and Cochrane Controlled Trials Register databases in February 2012. According to MEDLINE search, the first publication of the ICI 204,636 (the drug code of quetiapine) was in 1991. The searches, therefore, covered the period of 1991- February 2012. Searches were limited to humans and adults only. Additional studies were also searched from the databases of AstraZeneca, the producer of the original quetiapine. References of the articles obtained by any means were searched. All relevant randomized-controlled trials (RCTs) and clinical-controlled trials (CCTs) were included.

\section{Searches}

The MEDLINE search strategies for optimal sensitivity in identifying randomized clinical trials used the following words and phrases: [(quetiapine) OR (seroquel)] AND [(major depressive disorder) OR (MDD) OR (major depression) OR (severe depressive episode)]. Similarly, these search strategies were used in the rest of databases.

\section{Study selection}

Two reviewers (NM and BM) independently examined all abstracts identified by electronic searches to determine those meeting the eligible studies described above. The full-text articles of relevant studies were obtained. The reviewers then independently assessed all full study reports. Disputes were resolved through consensus.

\section{Data collection process}

We developed a data extraction form. A reviewer (NM) extracted the data into the form. The second reviewer (BM) checked the extracted data. Any disputes between reviewers were resolved by consensus. If no agreement could be reached, the third author (MS) would decide.

\section{Data items}

Extracted data obtained from each trial included: (1) study details needed for validity assessment; (2) baseline characteristics of participants, diagnostic criteria, study design and inclusion/exclusion criteria; (3) form, dose, and duration of quetiapine compared to placebo; (4) outcomes of interest. As far as possible, the intention-to treat results were recorded.

\section{Risk of bias in individual studies}

Two reviewers (NM and BM) rated the internal validity (quality) of each eligible randomized trial. Based on the Cochrane Collaboration quality assessment for trials, risks of bias were determined by: 1) the quality of randomization, 2) concealment of allocation, 3) blinding, 4) baseline similarity, 5) intention-to-treat analysis, 6) free of selective reporting, and 7) free of other biases [35]. Studies with two risks or less were included in the analysis.

\section{Summary measures}

Outcomes of interest included efficacy, acceptability and tolerability. Efficacy measures relied on the mean change scores of a rating scale for MDD and the response rates defined by any set of criteria. Since acceptability and tolerability have been used interchangeably, both terms were specifically defined. Similar to a previous meta-analysis, the acceptability in this review was derived from the overall discontinuation rate [17]. The tolerability, frequently defined as a measure of antidepressant side effects [36], was drawn from the discontinuation rate due to adverse events.

Relative risks (RRs), the ratios of the probability of the event occurring in the experimental (intervention) group versus the controlled group, with the 95\% confidence interval $(95 \% \mathrm{CI})$ were used for synthesizing the dichotomous data. A relative risk of one indicates no difference between comparison groups. For an unwanted outcome, an RR lesser than one suggests the less likelihood of the occurrence of such outcome. In this meta-analysis, relative risks were used to compare the response rates, overall discontinuation rates, and discontinuation rates due to adverse events between groups. In addition to the measure of efficacy, the number needed to treat (NNT), the number of patients who must receive a particular therapy for one to benefit, was also calculated.

A weighted or standardized mean difference (WMD or SMD) is the difference between two means divided by an estimate of the within group standard deviation; this mean difference, with $95 \% \mathrm{CI}$, was used for the synthesis of continuous data. When an outcome is measured by different instruments across studies, it may not be possible to compare or combine study results directly. By expressing the effect as a standardized value, the results can be combined since they have no unit. As a function 
of direct comparison or combination of trials, a WMD is plausible when the same instrument of measurement was used. In the present review, the WMDs or the SMDs were planned to be calculated if the retrieved studies used the same rating scale or different rating scales, respectively. When a standard deviation (SD) for mean change of depressive rating score was not provided, we estimated the SD by using direct substitution or any statistical method [37].

\section{Synthesis of results}

Both fixed effect and random effect models can be used for data synthesis. For the fixed effect approach, we assume that all included studies share a common effect size. The ignorance of this between-study variation is also the main difference from a random effect model. For most instances, the assumption of one true effect size may be implausible. Although the included studies are relatively similar, there is generally no reason to assume that they are exactly the same. For this reason, a random effect model was applied for the synthesis of data in this review.

\section{Risk of bias across studies}

To detect the reporting biases, a funnel plot, a simple plot of the intervention effect estimating from individual studies against some measure of each study's size or precision [38], was applied.

\section{Test of heterogeneity}

A test of heterogeneity is necessary for evaluating the similarity of the study results. Before conducting this meta-analysis, we hypothesized that the effect size may differ due to the methodological quality of the studies. We checked whether the study results had greater differences than expected by chance alone. This was done by observing the results presented by graphical display and using the test of heterogeneity. An $\mathrm{I}^{2}$ of $50 \%$ or higher was considered as significant heterogeneity of results.

\section{Statistical software}

All analyses were conducted using the RevMan 5.1 (The Nordic Cochrane Centre, Copenhagen, Denmark).

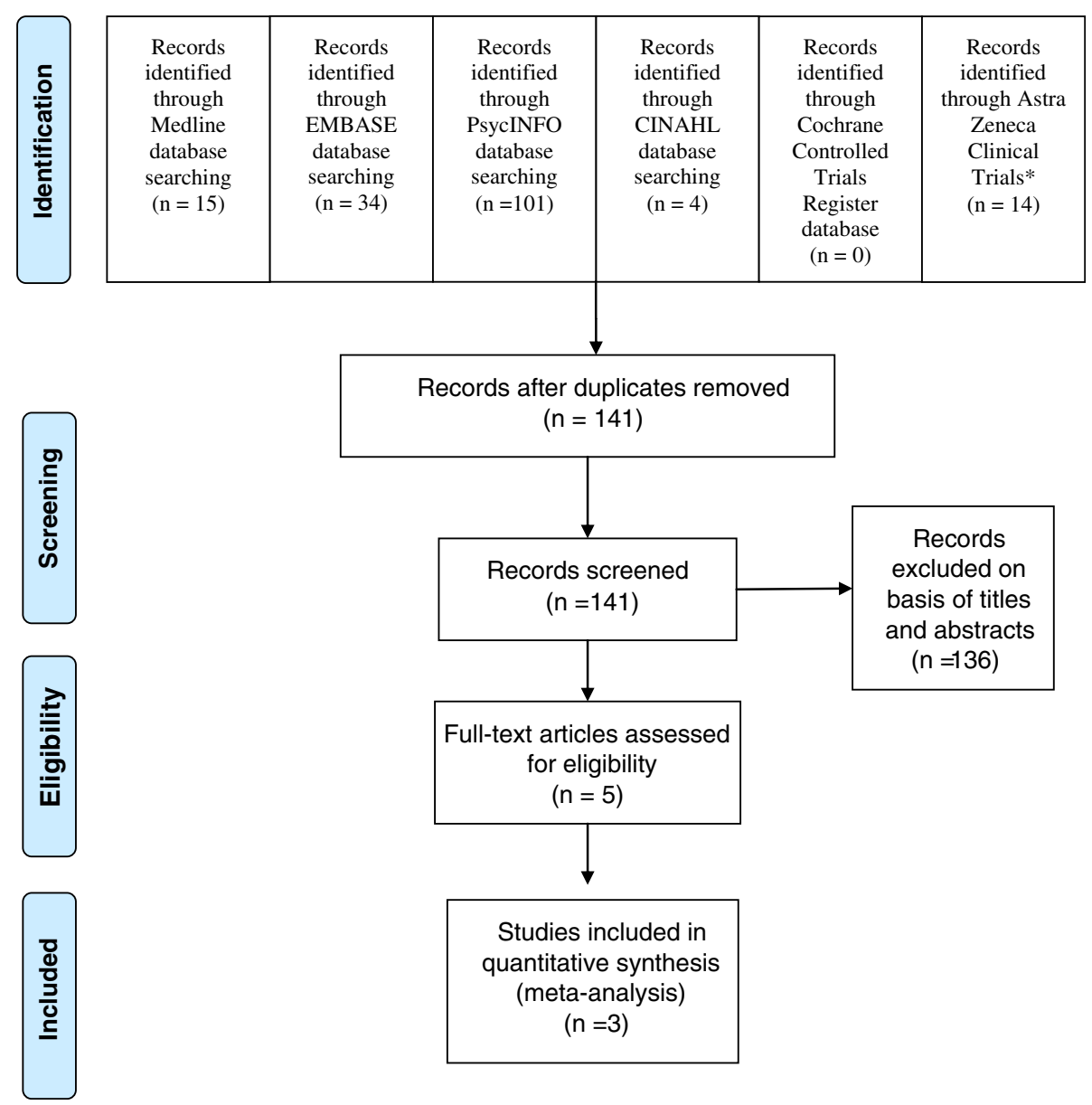

Figure 1 Flow diagram of study * http://www.astrazenecaclinicaltrials.com/drug-products/seroquel/. 
Table 1 The important characteristics of controlled trials of quetiapine in major depressive disorder

\begin{tabular}{|c|c|c|c|c|c|c|c|c|}
\hline $\begin{array}{l}\text { Study } \\
\text { (author, } \\
\text { year) }\end{array}$ & $\begin{array}{l}\text { Number } \\
\text { of } \\
\text { patients }\end{array}$ & $\begin{array}{l}\text { Age of } \\
\text { subjects } \\
\text { (years) }\end{array}$ & $\begin{array}{l}\text { Study } \\
\text { duration } \\
\text { (weeks) }\end{array}$ & Drug /Dose & $\begin{array}{l}\text { Diagnostic } \\
\text { criteria }\end{array}$ & $\begin{array}{l}\text { Respond } \\
\text { criteria }\end{array}$ & $\begin{array}{l}\text { Remission } \\
\text { criteria }\end{array}$ & Outcome measures \\
\hline $\begin{array}{l}\text { Cutler AJ } \\
2009\end{array}$ & 461 & $18-65$ & 8 & $\begin{array}{l}\text { Quetiapine XR/ } \\
150 \text { and } 300 \mathrm{mg} / \\
\text { day }\end{array}$ & DSM IV & $\begin{array}{l}\geq 50 \% \\
\text { reduction in } \\
\text { MADRS }\end{array}$ & $\begin{array}{l}\text { MADRS } \leq \\
8\end{array}$ & $\begin{array}{l}\text { MADRS, HAM-D, HAM-A, CGI-S, CGI-I, } \\
\text { PSQI, SAS, BARS, CSFQ, 18-item TDSS } \\
\text { scale }\end{array}$ \\
\hline $\begin{array}{l}\text { Weisler R } \\
2009\end{array}$ & 700 & $18-65$ & 8 & $\begin{array}{l}\text { Quetiapine XR/ } \\
50,150 \text { and } 300 \\
\text { mg/day }\end{array}$ & DSM IV & $\begin{array}{l}\geq 50 \% \\
\text { reduction in } \\
\text { MADRS }\end{array}$ & $\begin{array}{l}\text { MADRS } \leq \\
8\end{array}$ & $\begin{array}{l}\text { MADRS, HAM-D, HAM-A, CGI-S, CGI-I, } \\
\text { PSQI, SAS, BARS, CSFQ, Q-LES-Q, 18- } \\
\text { item TDSS scale }\end{array}$ \\
\hline $\begin{array}{l}\text { Bortnick B } \\
2011\end{array}$ & 299 & $18-65$ & 10 & $\begin{array}{l}\text { Quetiapine XR/ } \\
150 \text { to } 300 \mathrm{mg} / \\
\text { day }\end{array}$ & DSM IV & $\begin{array}{l}\geq 50 \% \\
\text { reduction in } \\
\text { MADRS }\end{array}$ & $\begin{array}{l}\text { MADRS } \leq \\
8\end{array}$ & $\begin{array}{l}\text { MADRS, HAM-D, HAM-A, CGI-S, CGI-I, } \\
\text { PSQI, SAS, BARS, CSFQ, Q-LES-Q, 18- } \\
\text { item TDSS scale }\end{array}$ \\
\hline
\end{tabular}

MADRS = Montgomery-Åsberg Depression Rating Scale; HAM-D = Hamilton Rating Scale for Depression; HAM-A = Hamilton Rating Scale for Anxiety; CGI-S= Clinical Global Impression-Severity of Illness; CGI-I = Clinical Global Impression-Improvement scale; PSQI = Pittsburgh Sleep Quality Index; SAS = Simpson-Angus Scale, BARS = Barnes Akathisia Rating Scale; CSFQ = Changes in Sexual Functioning Questionnaire; Q-LES-Q = Quality of Life Enjoyment Satisfaction Questionnaire; TDSS scale $=$ Treatment discontinuation.

\section{Results}

\section{Study selection}

Database searches provided a total of 168 citations (Medline $=15$ studies, EMBASE $=34$ studies, $\mathrm{CINHL}=4$ studies, PsycINFO=101 studies, Cochrane Controlled Trials Register $=0$ study and Astra Zeneca Clinical Trials =14) (see Figure 1). After the remove of duplicates, 141 trials remained. By reviewing the titles and abstracts, 136 trials were excluded since they clearly did not meet the criteria. Full papers of five studies were examined [30-33,39], two studies were excluded since one was a study of maintenance treatment [30] and the other studied in geriatric patients [39], only three trials [31-33], therefore, were included in the review. No relevant, unpublished study meeting the inclusion criteria was identified.

\section{Study characteristics}

The study periods of the three trials ranged from 8 to 11 weeks. All studies had wash-out periods (up to 4 weeks) for discontinuing psychotropic medications followed by randomization and a 2-week, post-treatment, drugdiscontinuation phase.

Of 1,497 participants, 64.3\% were female. All participants were outpatients with MDD, single or recurrent episode. None of them had treatment-resistant depression. Mean ages of the quetiapine and placebo groups were $41.38(\mathrm{SD}=11.68)$ and $41.66(\mathrm{SD}=11.72)$, respectively. The patients in all studies were treated with the extended-release (XR) form of quetiapine. The dosage of quetiapine XR ranged from 50 to $300 \mathrm{mg} /$ day. Table 1 shows the main characteristics of included studies.

Since all three studies reported mean change scores of Montgomery-Asberg Depression Rating Scale (MARDS) and Hamilton Depression Rating Scale (HAM-D), the WMDs of mean change scores were calculated and synthesized. Remission rate, response rates, overall discontinuation rates, and discontinuation due to adverse events were also reported in all studies.

\section{Risk of bias within studies}

All studies applied the technique of randomization, double-blind placebo control, and modified intention-to treat analysis. Dropout data and baseline similarity were reported in all studies. Only two studies [32,33] reported sequence generation of randomization and allocation concealment. No risk of bias for baseline similarity and other bias were found (see Table 2). As all studies had low risks of bias, the data of all three trials were included in the analysis.

\section{Results of individual studies}

The response rate of the quetiapine-treated group in each study was significantly greater than that of the placebo-treated group (see Figure 2). However, the remission rate of the quetiapine-treated group in each study was not significantly higher than that of the placebo-treated group (see Figure 3). The mean change MADRS and HAM-D scores of the quetiapine-treated group in each study were higher than that of the placebo-treated group (see Figures 4 and 5).

Table 2 Risk of bias summary of controlled trials of quetiapine in major depressive disorder

\begin{tabular}{lllllllll}
\hline Study & \multicolumn{7}{c}{ Issues of bias } \\
\cline { 2 - 8 } & $\mathbf{1}$ & $\mathbf{2}$ & $\mathbf{3}$ & $\mathbf{4}$ & $\mathbf{5}$ & $\mathbf{6}$ & $\mathbf{7}$ & $\mathbf{8}$ \\
\hline Cutler AJ 2009 & N & N & N & N & N & N & N & N \\
Weisler R 2009 & N & N & N & N & N & N & N & N \\
Bortnick B 2011 & N/A & N/A & N & N & N & N & N & N \\
\hline
\end{tabular}

$1=$ Adequate sequence generation; 2 = Allocation concealment; $3=$ =Blinding (Subjective outcome); 4 = Dropout data addressed; 5 = Free of selective reporting; $6=$ Free of other bias; $7=$ Baseline similarity; $8=$ Intention-to-treat analysis or modified intention-to-treat analysis; N/A = not available; $\mathrm{N}=\mathrm{No}$ risk of bias. 


\begin{tabular}{|c|c|c|c|c|c|c|c|c|}
\hline \multirow{2}{*}{$\begin{array}{l}\text { Study or Subgroup } \\
\text { Cutler } 2009\end{array}$} & \multicolumn{2}{|c|}{ Quetiapine } & \multicolumn{2}{|c|}{ Placebo } & Weight & $\begin{array}{c}\text { Risk Ratio } \\
\text { M-H, Random, } 95 \% \mathrm{Cl}\end{array}$ & \multicolumn{2}{|c|}{$\begin{array}{c}\text { Risk Ratio } \\
\text { M-H, Random, } 95 \% \mathrm{Cl}\end{array}$} \\
\hline & 164 & 294 & 55 & 152 & $31.4 \%$ & $1.54[1.22,1.95]$ & & 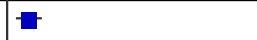 \\
\hline Weisler 2009 & 241 & 522 & 53 & 178 & $29.0 \%$ & $1.55[1.21,1.98]$ & & $=$ \\
\hline Bortnick 2011 & 91 & 147 & 73 & 152 & $39.7 \%$ & $1.29[1.05,1.59]$ & & $\theta$ \\
\hline Total $(95 \% \mathrm{Cl})$ & & 963 & & 482 & $100.0 \%$ & $1.44[1.26,1.64]$ & & 1 \\
\hline Total events & 496 & & 181 & & & & & \\
\hline $\begin{array}{l}\text { Heterogeneity: } \mathrm{Tau}^{2}= \\
\text { Test for overall effect }\end{array}$ & $\begin{array}{l}.00 ; \mathrm{Chi}^{2} \\
=5.43(\mathrm{~F}\end{array}$ & $\begin{array}{l}=1.83 \\
<0.00\end{array}$ & $\begin{array}{l}d f=2(P \\
001)\end{array}$ & $=0.40)$ & $I^{2}=0 \%$ & & $\begin{array}{lc}\longmapsto \\
0.01 & 0.1 \\
\text { Favours placebo }\end{array}$ & $\begin{array}{ccc}1 & 10 & 100 \\
\text { Favours quetiapine }\end{array}$ \\
\hline
\end{tabular}

Figure 2 Comparison of relative risk (95\% confidence interval) for clinical response rates in patients with MDD: quetiapine vs. placebo.

\section{Synthesis of results \\ Efficacy}

No significant heterogeneity was found on all efficacy outcomes, except HAM-D scores. The pooled response rate of the quetiapine -treated group was significantly greater than that of the placebo-treated group [RR (95\% $\mathrm{CI}$ ) of $\left.1.44(1.26,1.64), \mathrm{I}^{2}=0 \%\right]$ (see Figure 2). The pooled remission rate of the quetiapine-treated group was also significantly greater than that of the placebotreated group [RR $(95 \% \mathrm{CI})$ of $\left.1.37(1.12,1.68), \mathrm{I}^{2}=0 \%\right]$ (see Figure 3). The pooled mean change MADRS score of the quetiapine-treated group was significantly higher than that of the placebo-treated group [WMD $(95 \% \mathrm{CI})$ of $-3.37(-3.95,-2.79), I^{2}=0 \%$ ] (see Figure 4$)$. The pooled mean change HAM-D score of the quetiapine-treated group was also significantly higher than that of the placebo-treated group [WMD $(95 \% \mathrm{CI})$ of $-2.46(-3.47$, $-1.45), \mathrm{I}^{2}=89 \%$ ] (see Figure 5 ). With respect to sleep time, the pooled mean change Pittsburgh Sleep Quality Index (PSQI) score of the quetiapine-treated group was also significantly higher than that of the placebo-treated group [WMD $(95 \% \mathrm{CI})$ of $\left.-1.21(-1.81,-0.61), \mathrm{I}^{2}=48 \%\right]$. According to the pooled response rate obtained from all trials, the NNT $(95 \% \mathrm{CI})$ was $7.2(5.2-11.7)$.

\section{Discontinuation rates}

There was no significant heterogeneity on both discontinuation outcomes. The pooled overall discontinuation rate of the quetiapine group was not significantly different from that of the placebo group [RR $(95 \% \mathrm{CI})$ of 1.16 $\left.(0.97,1.39), \mathrm{I}^{2}=0 \%\right]$. However, the pooled discontinuation rate due to adverse events in the quetiapine group was significantly higher than that of the placebo group [RR $(95 \% \mathrm{CI})$ of $\left.2.90(1.87,4.48), \mathrm{I}^{2}=0 \%\right]$.

\section{Risk of bias across studies}

Tests for funnel plot asymmetry is normally used in the meta-analysis with at least 10 studies included; the power of the tests is too low to distinguish chance from real asymmetry, if fewer studies [38]. Because only 3 studies were included in this analysis, a test for funnel plot, therefore, was not done.

\section{Discussion}

Our review found only three randomized, placebocontrolled trials of quetiapine carried out in adult patients with MDD. All studies had the same study designs. The preliminary findings of this meta-analysis suggest that quetiapine monotherapy is effective for adult patients with MDD. Based on the pooled response rates, the NNT of 7.2 indicates that, by average, every 1 in 8 patients with MDD will respond to quetiapine treatment. The high dropout rate due to adverse events suggests that some MDD patients may not be able to tolerate quetiapine XR. Due to the balance of its efficacy benefit and risk of side

\begin{tabular}{|c|c|c|c|c|c|c|c|c|}
\hline Study or Subgroup & \multicolumn{2}{|c|}{ Quetiapine } & \multicolumn{2}{|c|}{ Placebo } & Weight & $\begin{array}{c}\text { Risk Ratio } \\
\text { M-H, Random, } 95 \% \mathrm{Cl}\end{array}$ & \multicolumn{2}{|c|}{$\begin{array}{c}\text { Risk Ratio } \\
\text { M-H, Random, } 95 \% \text { Cl } \\
\end{array}$} \\
\hline Cutler 2009 & 85 & 294 & 31 & 152 & $31.7 \%$ & $1.42[0.99,2.04]$ & & $E$ \\
\hline Weisler 2009 & 127 & 522 & 33 & 178 & $35.2 \%$ & $1.31[0.93,1.85]$ & & $f-$ \\
\hline Bortnick 2011 & 51 & 147 & 38 & 152 & $33.1 \%$ & $1.39[0.97,1.98]$ & & + \\
\hline Total $(95 \% \mathrm{Cl})$ & & 963 & & 482 & $100.0 \%$ & $1.37[1.12,1.68]$ & & 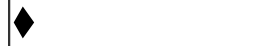 \\
\hline Total events & 263 & & 102 & & & & & \\
\hline $\begin{array}{l}\text { Heterogeneity: } \mathrm{Tau}^{2}= \\
\text { Test for overall effect: }\end{array}$ & $\begin{array}{l}0.00 ; \mathrm{Chi}^{2} \\
\mathrm{Z}=3.03(\mathrm{~F}\end{array}$ & $\begin{array}{l}=0.10 \\
=0.00\end{array}$ & $\begin{array}{l}\mathrm{df}=2(\mathrm{P} \\
2)\end{array}$ & $=0.95)$ & $; I^{2}=0 \%$ & & $\begin{array}{lc}0.01 & 0.1 \\
\text { Favours placebo } & 1\end{array}$ & $\begin{array}{lcc}1 & 10 & 100 \\
& \text { Favours quetiapine }\end{array}$ \\
\hline
\end{tabular}




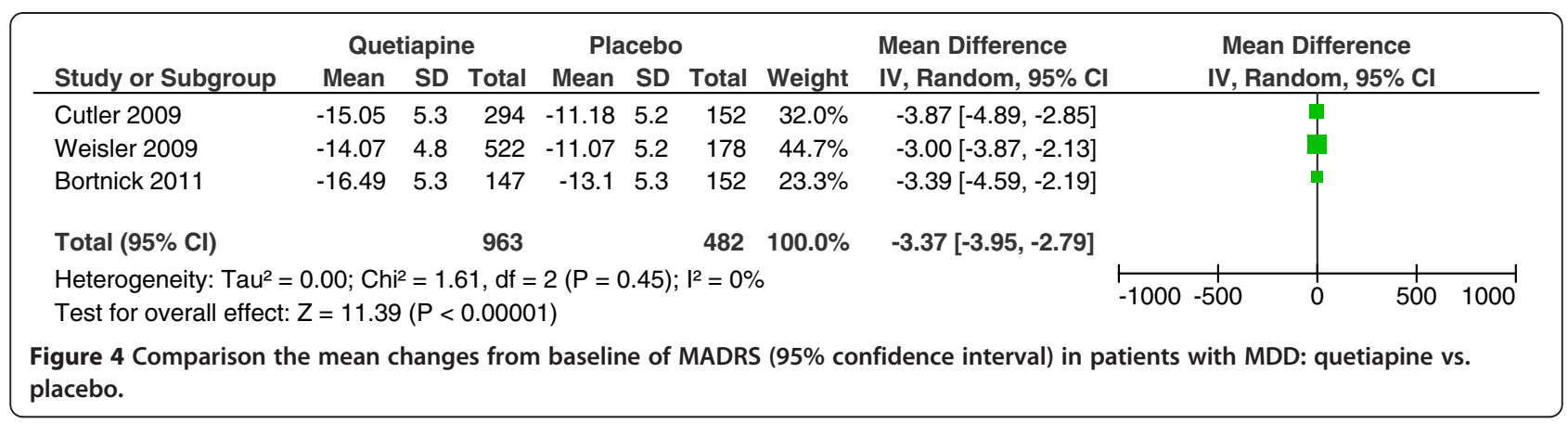

effects, as the overall discontinuation rate shown, the acceptability of this agent is not more than placebo.

In this review, the pooled response rate for quetiapine monotherapy in MDD patients (51.51\%) was superior to placebo (37.55\%). Similarly, a meta-analysis of 7 RCTs found that the response rates of bupropion and SSRIs treatment in MDD patients were 62 and 63\%, respectively, compared with $51 \%$ for placebo [40]. The remission rate of quetiapine treatment $(27.31 \%)$ is also greater than that of placebo one (21.16\%). Previous metaanalyses found that the remission rates of TCAs, SSRIs, and SNRIs were 44.1, 37.7 and 31-55\% respectively [41]. It should be noted that not only the response and remission rates of quetiapine treatment but also those of placebo treatment found in this study were lower than previous findings. Therefore, the cross-trial comparisons of the response and remission rates of quetiapine with those of other antidepressants may not be justified.

Absolute risk reduction (ARR) is the difference between the control group's event rate and the experimental group's event rate. As a measure of the size of difference between two treatments (e.g., antidepressants and placebo), the ARR may be a logical method for comparing the remission and response rates of antidepressants across studies. Based on the ARR, quetiapine increases the response rate for $13.96 \%$ (51.51\% for quetiapine group vs. $37.55 \%$ for placebo group), while bupropion and SSRIs increase the response rates for $11 \%$ and $12 \%$, respectively (62\% for bupropion group and $63 \%$ for SSRI group vs. $51 \%$ for placebo group) [40].
Regarding the response rates of other antidepressants in adults with MDD, the NNTs of fluoxetine and venlafaxine are between 5 and 7, which are comparable to the NNT of 8 for the quetiapine treatment in this population [42]. Not surprisingly, as an inverse of the ARR, the comparable of ARRs between quetiapine and other antidepressants, the NNTs of these agents are, therefore, comparable. However, the ARR for the remission rate of quetiapine treatment [6.15\% (27.31\% for quetiapine vs. $21.16 \%$ for placebo)] is relatively lower than those of SSRIs and bupropion [11\% (47\% for SSRIs and bupropion vs. $36 \%$ for placebo)] [40]. It is not yet known whether these differences reflect the true lower remission rate of quetiapine treatment or only the dissimilarity of participants and study designs among the studies.

Similar to other antidepressants, the acceptability of quetiapine for the treatment of MDD is not higher than that of placebo. The nonsignificant differences in this respect have been found in a number of meta-analyses of paroxetine [43] and duloxetine [44] and TCAs [10] for the treatment of MDD. The low tolerability of quetiapine treatment for MDD is also similar to previous findings of other antidepressants, e.g. TCAs [45], SSRIs [45] and SNRIs [46,47]. These lines of evidence suggest that almost all antidepressants, including quetiapine, have the same profile of comparable acceptability to and less tolerability than placebo.

Sleep disturbance is common in MDD and may complicate its treatment. Up to $31 \%$ of MDD patients may have insomnia [48]. In addition, insomnia is a common

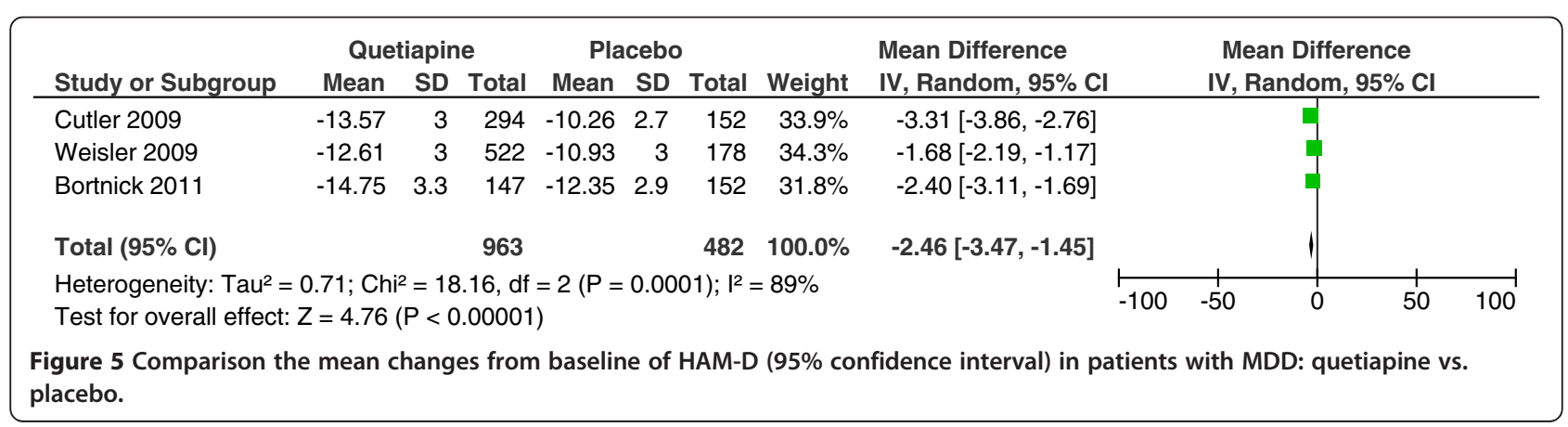


adverse effect of many antidepressants, e.g., SSRIs [49] and SNRIs [50]. The findings of sleep quality improved by quetiapine suggests an advantage of quetiapine for the treatment of MDD.

There were several limitations of this review. Firstly, the doses of quetiapine were different across the included studies. While a study used a flexible dose with titration, the others applied fixed and multiple doses in several arms. Secondly, this meta-analysis included only three RCTs sponsored by a pharmaceutical company holding the patent of quetiapine XR. These results, therefore, should be viewed as the very preliminary findings. Thirdly, although all studies adhered to the same methods of double blindness/randomization, had similar baseline characteristics, and applied the intention-totreat analysis or modified intention-to-treat analysis for the data analyses, 1 of 3 studies did not report an adequate sequence generation of randomization and the allocation concealment. Fourthly, as with all metaanalyses, publication bias must be considered. However, due to the small number of included studies, we did not assess the possibility of publication bias [38].

\section{Conclusions}

Based on the limited evidence obtained from three RCTs, quetiapine XR is effective for adult patients with MDD. The high dropout rate due to adverse events suggests that some MDD patients may not be able to tolerate quetiapine XR. Due to the balance of its efficacy benefit and risk of side effects, as the overall discontinuation rate shown, the acceptability of this agent is not more than placebo. These results should be viewed as the very preliminary one. Further studies in this area are warranted.

\section{Competing interest}

NM has received travel reimbursement from GlaxoSmithKline, Pfizer, JanssenCilag and Lundbeck. BM has received honoraria and/or travel reimbursement from GlaxoSmithKline, and Pfizer. MS has received honoraria, consultancy fees, research grants, and/or travel reimbursement from AstraZeneca, GlaxoSmithKline, Pfizer, Janssen-Cilag, Johnson \& Johnson, Lundbeck, Thai-Otsuka, Sanofi-Aventis, and Servier. SDM has received honoraria, consultancy fees and research grants from Astra Zeneca, Eli Lilly, JanssenCilag, Sanofi-Aventis, Novartis and Wyeth.

\section{Authors' contributions}

All authors conceived the idea, prepared the study protocol, prepared the manuscript, and approved the manuscript in its current form. NM and BM searched the databases, extracted the data, and analysed the data.

\section{Funding}

This review had no funding.

\section{Author details}

${ }^{1}$ Department of Psychiatry, Faculty of Medicine, Chiang Mai University, Chiang Mai, Thailand. ${ }^{2}$ Brandon Lane Neuropsychiatry Clinic, Durham, United Kingdom.

Received: 28 February 2012 Accepted: 20 September 2012

Published: 27 September 2012

\section{References}

1. Waraich P, Goldner EM, Somers JM, Hsu L: Prevalence and incidence studies of mood disorders: a systematic review of the literature. Can J Psychiatr 2004, 49(2):124-138.

2. Culpepper L: Understanding the burden of depression. J Clin Psychiatr 2011, 72(6):e19.

3. Rush AJ, Wisniewski SR, Zisook S, Fava M, Sung SC, Haley CL, Chan HN, Gilmer WS, Warden D, Nierenberg AA, et al: Is prior course of illness relevant to acute or longer-term outcomes in depressed out-patients? A STAR*D report. Psychol Med 2011, 42(6):1-19.

4. Ustün TB, Ayuso-Mateos JL, Chatterii S, Mathers C, Murray CJ: Global burden of depressive disorders in the year 2000. Br J Psychiatry 2004, 184:386-392.

5. Bech P, Cialdella P: Citalopram in depression-meta-analysis of intended and unintended effects. Int Clin Psychopharmacol 1992, 6(Suppl 5):45-54.

6. Tignol J, Stoker MJ, Dunbar GC: Paroxetine in the treatment of melancholia and severe depression. Int Clin Psychopharmacol 1992, 7(2):91-94.

7. Entsuah $A R$, Rudolph $R L$, Chitra R: Effectiveness of venlafaxine treatment in a broad spectrum of depressed patients: a meta-analysis. Psychopharmacol Bull 1995, 31(4):759-766.

8. Mallinckrodt CH, Watkin JG, Liu C, Wohlreich MM, Raskin J: Duloxetine in the treatment of Major Depressive Disorder: a comparison of efficacy in patients with and without melancholic features. BMC Psychiatr 2005, 5:1.

9. Storosum JG, Elferink AJ, van Zwieten BJ, van den Brink W, Gersons BP, van Strik R, Broekmans AW: Short-term efficacy of tricyclic antidepressants revisited: a meta-analytic study. Eur Neuropsychopharmacol 2001, 11(2):173-180.

10. Furukawa TA, McGuire H, Barbui C: Meta-analysis of effects and side effects of low dosage tricyclic antidepressants in depression: systematic review. BMJ 2002, 325(7371):991.

11. Furukawa T, McGuire H, Barbui C: Low dosage tricyclic antidepressants for depression. Cochrane Database Syst Rev 2003, (3):CD003197.

12. Papakostas Gl, Fava M: A metaanalysis of clinical trials comparing moclobemide with selective serotonin reuptake inhibitors for the treatment of major depressive disorder. Can J Psychiatr 2006, 51(12):783-790.

13. Entsuah $A R$, Huang $H$, Thase ME: Response and remission rates in different subpopulations with major depressive disorder administered venlafaxine, selective serotonin reuptake inhibitors, or placebo. J Clin Psychiatr 2001, 62(11):869-877.

14. Thase ME, Entsuah $A R$, Rudolph RL: Remission rates during treatment with venlafaxine or selective serotonin reuptake inhibitors. Br J Psychiatry 2001, 178:234-241.

15. Papakostas Gl, Charles D, Fava M: Are typical starting doses of the selective serotonin reuptake inhibitors sub-optimal? A meta-analysis of randomized, double-blind, placebo-controlled, dose-finding studies in major depressive disorder. World J Biol Psychiatr 2010, 11 (2 Pt 2):300-307.

16. Papakostas GI, Nelson JC, Kasper S, Moller HJ: A meta-analysis of clinical trials comparing reboxetine, a norepinephrine reuptake inhibitor, with selective serotonin reuptake inhibitors for the treatment of major depressive disorder. Eur Neuropsychopharmacol 2008, 18(2):122-127.

17. Cipriani A, Furukawa TA, Salanti G, Geddes JR, Higgins JP, Churchill R, Watanabe N, Nakagawa A, Omori IM, McGuire H, et al: Comparative efficacy and acceptability of 12 new-generation antidepressants: a multiple-treatments meta-analysis. Lancet 2009, 373(9665):746-758.

18. Nutt DJ: The role of dopamine and norepinephrine in depression and antidepressant treatment. J Clin Psychiatr 2006, 67(Suppl 6):3-8.

19. Montgomery SA: The under-recognized role of dopamine in the treatment of major depressive disorder. Int Clin Psychopharmacol 2008, 23(2):63-69.

20. Horacek J, Bubenikova-Valesova V, Kopecek M, Palenicek T, Dockery C, Mohr P, Hoschl C: Mechanism of action of atypical antipsychotic drugs and the neurobiology of schizophrenia. CNS Drugs 2006, 20(5):389-409.

21. Jensen $\mathrm{NH}$, Rodriguiz RM, Caron MG, Wetsel WC, Rothman RB, Roth BL: $\mathrm{N}$-desalkylquetiapine, a potent norepinephrine reuptake inhibitor and partial 5-HT1A agonist, as a putative mediator of quetiapine's antidepressant activity. Neuropsychopharmacology 2008, 33(10):2303-2312

22. Bakken GV, Rudberg I, Molden E, Refsum H, Hermann M: Pharmacokinetic variability of quetiapine and the active metabolite $\mathrm{N}$-desalkylquetiapine in psychiatric patients. Ther Drug Monit 2011, 33(2):222-226.

23. Goldstein JM, Nyberg S, Brecher M: Preclinical mechanisms for the broad spectrum of antipsychotic, antidepressant and mood stabilizing properties of Seroquel. Eur Psychiatr 2008, 23(suppl 2):S202. 
24. Altamura AC, Moliterno D, Paletta S, Buoli M, Dell'osso B, Mauri MC, Bareggi SR: Effect of quetiapine and norquetiapine on anxiety and depression in major psychoses using a pharmacokinetic approach: a prospective observational study. Clin Drug Investig 2012, 32(3):213-219.

25. Addington DE, Mohamed S, Rosenheck RA, Davis SM, Stroup TS, McEvoy JP, Swartz MS, Lieberman JA: Impact of second-generation antipsychotics and perphenazine on depressive symptoms in a randomized trial of treatment for chronic schizophrenia. J Clin Psychiatr 2011, 72(1):75-80.

26. Chiesa A, Chierzi F, De Ronchi D, Serretti A: Quetiapine for bipolar depression: a systematic review and meta-analysis. Int Clin Psychopharmacol 2012, 27(2):76-90.

27. Sanford M, Keating GM: Quetiapine: a review of its use in the management of bipolar depression. CNS Drugs 2012, 26(5):435-460.

28. Kjelby E, Jorgensen HA, Kroken RA, Loberg EM, Johnsen E: Anti-depressive effectiveness of olanzapine, quetiapine, risperidone and ziprasidone: a pragmatic, randomized trial. BMC Psychiatr 2011, 11:145

29. Amit BH, Weizman A: Antidepressant treatment for acute bipolar depression: an update. Depress Res Treat 2012, 2012:684725.

30. Liebowitz M, Lam RW, Lepola U, Datto C, Sweitzer D, Eriksson H: Efficacy and tolerability of extended release quetiapine fumarate monotherapy as maintenance treatment of major depressive disorder: a randomized, placebo-controlled trial. Depress Anxiety 2010, 27(10):964-976.

31. Bortnick B, El-Khalili N, Banov M, Adson D, Datto C, Raines S, Earley W, Eriksson $\mathrm{H}$ : Efficacy and tolerability of extended release quetiapine fumarate (quetiapine XR) monotherapy in major depressive disorder: a placebo-controlled, randomized study. J Affect Disord 2011, 128(1-2):83-94

32. Weisler R, Joyce M, McGill L, Lazarus A, Szamosi J, Eriksson H: Extended release quetiapine fumarate monotherapy for major depressive disorder: results of a double-blind, randomized, placebo-controlled study. CNS Spectr 2009, 14(6):299-313.

33. Cutler AJ, Montgomery SA, Feifel D, Lazarus A, Astrom M, Brecher M: Extended release quetiapine fumarate monotherapy in major depressive disorder: a placebo- and duloxetine-controlled study. J Clin Psychiatr 2009, 70(4):526-539.

34. Uher R, Farmer A, Maier W, Rietschel M, Hauser J, Marusic A, Mors O, Elkin A, Williamson RJ, Schmael C, et al: Measuring depression: comparison and integration of three scales in the GENDEP study. Psychol Med 2008, 38(2):289-300

35. Higgins JPT, Altman DG: Assessing risk of bias in included studies. In Cochrane Handbook for Systematic Reviews of Interventions. Version 5.1.0 (Updated March 2011). Edited by Higgins JPT, Green S. The Cochrane Collaboration; 2011 [http://www.cochrane-handbook.org].

36. Papakostas Gl: Tolerability of modern antidepressants. J Clin Psychiatry 2008, 69(E1):8-13.

37. Wiebe N, Vandermeer B, Platt RW, Klassen TP, Moher D, Barrowman NJ: A systematic review identifies a lack of standardization in methods for handling missing variance data. J Clin Epidemiol 2006, 59(4):342-353.

38. Sterne JAC, Egger M, Moher D: Addressing Reporting Biases. In Cochrane Handbook for Systematic Reviews of Interventions. Version 5.1.0 (Updated March 2011) edition. Edited by Higgins JPT, Green S. The Cochrane Collaboration; 2011 [http://www.cochrane-handbook.org]

39. A multi-center, double-blind, randomized, parallel-group, placebo-controlled phase III study of the efficacy and safety of quetiapine fumarate extended-release (Seroquel $X R^{\mathrm{TM}}$ ) as mono-therapy in the treatment of elderly patients with major depressive disorder (SAPPHIRESTUDY). AstraZeneca Clinical Trials, http://www. astrazenecaclinicaltrials.com/drug-products/seroquel/?itemId $=8543679$.

40. Thase ME, Haight BR, Richard N, Rockett CB, Mitton M, Modell JG, VanMete $S$, Harriett $A E$, Wang $Y$ : Remission rates following antidepressant therapy with bupropion or selective serotonin reuptake inhibitors: meta-analysis of original data from 7 randomized controlled trials. $J$ Clin Psychiatr 2005, 66(8):974-981.

41. Machado M, Iskedjian M, Ruiz I, Einarson TR: Remission, dropouts, and adverse drug reaction rates in major depressive disorder: a meta-analysis of head-to-head trials. Curr Med Res Opin 2006, 22(9):1825-1837.

42. Gibbons RD, Hur K, Brown CH, Davis JM, Mann JJ: Benefits From Antidepressants: Synthesis of 6-Week Patient-Level Outcomes From Double-blind Placebo-Controlled Randomized Trials of Fluoxetine and Venlafaxine. Arch Gen Psychiatry 2012, 69(6):572-579.

43. Barbui C, Furukawa TA, Cipriani A: Effectiveness of paroxetine in the treatment of acute major depression in adults: a systematic re-examination of published and unpublished data from randomized trials. CMAJ 2008, 178(3):296-305.

44. Mallinckrodt CH, Prakash A, Andorn AC, Watkin JG, Wohlreich MM: Duloxetine for the treatment of major depressive disorder: a closer look at efficacy and safety data across the approved dose range. J Psychiatr Res 2006, 40(4):337-348.

45. Arroll B, Elley CR, Fishman T, Goodyear-Smith FA, Kenealy T, Blashki G, Kerse $N$, Macgillivray S: Antidepressants versus placebo for depression in primary care. Cochrane Database Syst Rev 2009, (3):CD007954

46. Bauer M, Tharmanathan P, Volz HP, Moeller HJ, Freemantle N: The effect of venlafaxine compared with other antidepressants and placebo in the treatment of major depression: a meta-analysis. Eur Arch Psychiatr Clin Neurosci 2009, 259(3):172-185.

47. Stewart DE, Wohlreich MM, Mallinckrodt CH, Watkin JG, Kornstein SG: Duloxetine in the treatment of major depressive disorder: comparisons of safety and tolerability in male and female patients. J Affect Disord 2006, 94(1-3):183-189.

48. Breslau N, Roth T, Rosenthal L, Andreski P: Sleep disturbance and psychiatric disorders: a longitudinal epidemiological study of young adults. Biol Psychiatry 1996, 39(6):411-418

49. Beasley CM Jr, Nilsson ME, Koke SC, Gonzales JS: Efficacy, adverse events, and treatment discontinuations in fluoxetine clinical studies of major depression: a meta-analysis of the 20-mg/day dose. J Clin Psychiatr 2000, 61(10):722-728

50. Brecht S, Kajdasz D, Ball S, Thase ME: Clinical impact of duloxetine treatment on sleep in patients with major depressive disorder. Int Clin Psychopharmacol 2008, 23(6):317-324.

doi:10.1186/1471-244X-12-160

Cite this article as: Maneeton et al: Quetiapine monotherapy in acute phase for major depressive disorder: a meta-analysis of randomized, placebo-controlled trials. BMC Psychiatry 2012 12:160.

\section{Submit your next manuscript to BioMed Central and take full advantage of:}

- Convenient online submission

- Thorough peer review

- No space constraints or color figure charges

- Immediate publication on acceptance

- Inclusion in PubMed, CAS, Scopus and Google Scholar

- Research which is freely available for redistribution 